\title{
Eye injuries in children: the current picture
}

\author{
Caroline J MacEwen, Paul S Baines, Parul Desai
}

\begin{abstract}
Aims-To investigate the current causes and outcomes of paediatric ocular trauma.

Methods-A prospective observational study of all children admitted to hospital with ocular trauma in Scotland over a 1 year period.

Results-The commonest mechanism of injury was blunt trauma, accounting for $65 \%$ of the total. $60 \%$ of the patients were admitted with a hyphaema. Injuries necessitating admission occurred most frequently at home $(51 \%)$. Sporting activities were the commonest cause of injury in the 5-14 age group. There were no injuries caused by road traffic accidents or fireworks. Patients were admitted to hospital for a mean of 4.2 days (range 1-25 days). One $(1 \%)$ child had an acuity in the "visually impaired" range $(6 / 18-6 / 60)$ and one (1\%) was "blind" (6/60) in the affected eye. No child was bilaterally blinded by injury and none required blind or partial sight registration.

Conclusion-This study has shown that the incidence of eye injuries affecting children has fallen. The outcome of ocular trauma has improved significantly, and for the first time paediatric injuries appear to have a better prognosis than injuries affecting adults.

(Br F Ophthalmol 1999;83:933-936)
\end{abstract}

Eye injuries are an important cause of ocular morbidity in children, being a leading cause of non-congenital unilateral blindness in this age group. ${ }^{1}$ Such injuries cannot always be prevented, but by identifying any underlying factors in the aetiology of serious injuries, it may be possible to determine the most effective methods of reducing the incidence of visually damaging trauma.

This study was carried out as part of a larger

Department of

Ophthalmology,

Ninewells Hospital and

Medical School,

Dundee DD1 9SY

C J MacEwen

P S Baines

University of

Southampton,

Southampton General

Hospital,

Southampton

SO16 6YD

P Desai

Correspondence to:

Dr MacEwan.

Accepted for publication 15 March 1999

This study formed part of a larger prospective observational study of all patients admitted to hospital with ocular trauma in Scotland over a 1 year period, the full methods and results of which have been published elsewhere. ${ }^{2}{ }^{3}$ The entire population of Scotland constituted the study population and for the purposes of this study all children of 14 years or under were included in the analysis. All data were collected on standardised proforma by the admitting consultant and sent to a central base at the audit unit at the Royal College of Ophthalmologists and entered into a dedicated database. Data were collected on the demographic characteristics of patients, the cause, mechanism, and place of injury. Duration of hospital stay was recorded and the final visual acuity in the injured eye was documented. All patients were followed up for a minimum of 3 months.

\section{Results}

A total of 415 patients, who were Scottish residents, were admitted to hospital with an ocular injury during the study period, and of these 93 $(22 \%)$ were children less than 15 years of age. Sixty seven $(70 \%)$ of the children were male and $26(30 \%)$ were female. Fifteen $(16 \%)$ children were aged 4 years or less and $78(84 \%)$ were in the 5-14 age group.

The injury involved the left eye in 43 (46\%) cases, the right eye in $48(52 \%)$ cases, and both eyes in two $(2 \%)$ cases. The overall incidence for hospitalised ocular trauma was 8.85/ 100000 of the population in 1 year in the $0-14$ age group (compared with an overall incidence of $8.14 / 100000$ for the total population ${ }^{2}$ ).

\section{MECHANISM OF INJURY}

The mechanisms of injury sustained are shown in Table 1. The commonest type of injury was blunt trauma, accounting for $65 \%(n=60)$ of the total and penetrating injuries without retained foreign bodies were next $(24 \%$, $\mathrm{n}=22$ ), with all other types of injury being very rare. Fifty six $(60 \%)$ of the patients who were admitted had a hyphaema.

Table 1 Mechanism of injury

\begin{tabular}{llll}
\hline & \multicolumn{2}{l}{ Age group (years) } \\
\cline { 2 - 3 } & $0-4$ & $5-14$ & Total \\
\hline Blunt trauma & $7(47 \%)$ & $53(68 \%)$ & $60(65 \%)$ \\
Penetrating & $5(33 \%)$ & $17(22 \%)$ & $22(24 \%)$ \\
IOFB & $0(0 \%)$ & $4(5 \%)$ & $4(4 \%)$ \\
Chemical & $1(7 \%)$ & $0(0 \%)$ & $1(1 \%)$ \\
Other & $2(13 \%)$ & $2(2.5 \%)$ & $4(4 \%)$ \\
Unknown & $0(0 \%)$ & $2(2.5 \%)$ & $2(2 \%)$ \\
Total & 15 & 78 & 93 \\
\hline
\end{tabular}

^Intraocular foreign body.

Table 2 Place of injury

\begin{tabular}{llll}
\hline & \multicolumn{2}{l}{ Age groups (years) } & \\
\cline { 2 - 3 } & $0-4$ & $5-14$ & Total \\
\hline Home & $11(73 \%)$ & $36(46 \%)$ & $47(51 \%)$ \\
School & $0(0 \%)$ & $13(17 \%)$ & $13(14 \%)$ \\
Sport/leisure & $0(0 \%)$ & $9(12 \%)$ & $9(10 \%)$ \\
Pavement/street & $1(7 \%)$ & $8(11 \%)$ & $9(10 \%)$ \\
Other & $2(13 \%)$ & $6(8 \%)$ & $8(8 \%)$ \\
Unknown & $1(7 \%)$ & $6(8 \%)$ & $7(7 \%)$ \\
Total & 15 & 78 & 93 \\
\hline
\end{tabular}


Table 3 Cause of injury

\begin{tabular}{llll}
\hline & \multicolumn{2}{l}{ Age groups (years) } & \\
\cline { 2 - 3 } & $0-4$ & $5-14$ & Total \\
\hline Sport & $1(7 \%)$ & $14(18 \%)$ & $15(16 \%)$ \\
Assault & $0(0 \%)$ & $13(9 \%)$ & $13(14 \%)$ \\
Toy & $4(27 \%)$ & $7(9 \%)$ & $11(12 \%)$ \\
Tools & $3(20 \%)$ & $7(9 \%)$ & $10(10 \%)$ \\
Missile (stone) & 0 & $7(9 \%)$ & $7(7 \%)$ \\
Stick & $1(7 \%)$ & $4(5 \%)$ & $5(5 \%)$ \\
Fall & $1(7 \%)$ & $4(5 \%)$ & $5(5 \%)$ \\
Glass & $1(7 \%)$ & $3(4 \%)$ & $4(4 \%)$ \\
Airgun & 0 & $3(4 \%)$ & $3(3 \%)$ \\
Domestic chemicals & $1(7 \%)$ & $0(0 \%)$ & $1(1 \%)$ \\
Other & $3(20 \%)$ & $16(20 \%)$ & $19(20 \%)$ \\
Total & 15 & 78 & 93 \\
\hline
\end{tabular}

Table 4 Final visual acuities

\begin{tabular}{ll}
\hline Visual acuity & No (\%) \\
\hline$\geqslant 6 / 12$ & $82(88)$ \\
$6 / 18-6 / 60$ & $1(1)$ \\
$<6 / 60$ & $1(1)$ \\
Unknown & $9(10)$ \\
Total & 93 \\
\hline
\end{tabular}

PLACE OF INJURY

The place of injury is shown in Table 2. Overall, injuries necessitating admission occurred most frequently at home $(n=47,51 \%)$, and in the $0-4$ age group $73 \%(n=11)$ occurred at home.

\section{CAUSE OF INJURY}

The causes of injury are many and varied and no one cause can be identified as being predominant, especially in the younger age group. Sporting activities and, rather worryingly, assaults were the commonest causes in the 5-14 age group (Table 3 ). No injuries were caused by road traffic accidents or fireworks.

MANAGEMENT

Forty five children (48\%) required surgical management, 36 (39\%) were treated medically, and nine (10\%) were simply observed. There was no further information on the remaining three $(3 \%)$ patients. It was not possible to obtain this information as the data were collected anonymously and there was, therefore, no method of collecting data missed at the time of collection.

Patients were admitted to hospital for a mean of 4.2 days (range 1-25 days, mode 4 days). Nine patients were admitted for more than 1 week and of these six (67\%) required surgery.

\section{OUTCOME}

The final visual acuities were taken at time of final discharge. One (1\%) child had an acuity in the affected eye in the "visually impaired" range (6/18-6/60) and one (1\%) was "blind" $(<6 / 60)$ in the affected eye (Table 4$)$. The child who was rendered visually impaired had been assaulted, sustaining a penetrating injury, and the child who was blinded in the affected eye had fallen over at home and suffered a retinal detachment. No child was bilaterally blinded by injury and none required blind or partial sight registration.

\section{Discussion}

There have been no recent studies into the pattern of ocular injuries in children in the United Kingdom. Most of the recent work has concentrated on specific types of injury ${ }^{4-7}$ or on the epidemiology in other countries, ${ }^{8-14}$ which may not reflect our own experience, although the studies from North America may be the most relevant. The pattern of ocular injury in adults is known to have changed significantly with a reduction both in occupational trauma, which predominated in the first part of this century, ${ }^{15}$ and injuries occurring in road traffic accidents which became commoner latterly. ${ }^{16-18}$ These changes have occurred because of a combination of a changing socioeconomic climate with education to increase awareness of risk and legislation. Such factors may also influence childhood injuries although an excess risk of severe trauma among the very young has been recognised in many studies with more than one third of all eye injuries occurring in the paediatric age group. ${ }^{910-23}$ The larger study, of which this formed a substudy, found that $22.3 \%$ of those with serious eye injuries were in the $0-14$ age group (this age group makes up $18.8 \%$ of the entire population ${ }^{24}$ ). The incidence was $8.85 / 100000$ of the paediatric population which represents a reduction of at least $50 \%$ in the rate of injuries affecting children compared with previous work. ${ }^{825}$

Other studies have identified that boys tend to be affected more commonly than girls, ${ }^{6} 810-15212526$ which is in keeping with our findings. This probably reflects boys' more adventurous or possibly aggressive behaviour. School aged children are more susceptible than the younger age group as, although they are still relatively immature, these children are slightly more independent which may make them more vulnerable. ${ }^{810}$

The commonest location for an injury to take place was the home, accounting for more than $50 \%$ of all accidents. This was almost exclusively the place for preschool children injuries, but was also very common in schoolchildren, which reflects both the amount of time that all children spend at home and the risks around the home. Many of these risks remain unrecognised as most of the younger age group were injured by toys or domestic utensils which are found in any home. The domestic setting has previously been recognised as potentially dangerous, particularly with regard to penetrating injuries, ${ }^{6}$ but the incidence of injuries in the home in this study is significantly higher than found previously..$^{9} 1221$ This may be due to the climate in the United Kingdom, different standards of living or customs, or a change in pattern of injury.

Toys are a common cause of injury in the younger age group. In many cases the mechanism of injury is not clear, but may be due to inappropriate use of the toy, such as throwing it! However, toys are made to be used by children and, as such, inappropriate use should be considered and taken into account when devising safety standards for the manufacture of toys. Toys should be made safer and should be 
sold only if they comply with the appropriate British standard.

The injuries in the older age group were the result of a very diffuse number of causes, although participation in sports was the commonest cause of injury (Table 3). With increased time available for sport and leisure activities and more emphasis on fitness, sport is already recognised as being a leading cause of serious eye injury in Britain. ${ }^{26} 27$ Sport associated eye trauma is largely preventible and has been previously highlighted as a major cause of serious eye injury in the young age group. ${ }^{1021}$ Protective eye wear is available for a number of sports, although there are certain barriers to this such as poor education in this area and many sports are played on an informal and unsupervised basis by children. This explains why sport is the commonest cause of injury (Table 3) but sports/leisure facilities are not the commonest places for an injury to occur (Table 2).

Assaults have been recognised as a frequent cause of eye injury in the young. ${ }^{10} 1528 \mathrm{Al}-$ though the term assault suggests malicious intent, injuries in this category may be unintentional, usually aiming at another part of the body or a genuine accident. Children are not always aware of the possible consequences of their actions and effective countermeasures for injuries caused by assaults are very difficult to devise as the circumstances are not well delineated.

In this series blunt injuries predominate, most children being admitted because of hyphaema. This represents further evidence that there is a trend of increased incidence of blunt trauma in children ${ }^{8-10}$ compared with perforating injuries which were more common in the past. ${ }^{91529}$ This is a pattern to be welcomed as penetrating injuries, in general, carry a poorer prognosis as those who suffer from penetrating trauma are more likely to require surgery and to suffer from long term visual impairment. ${ }^{9}$ However, penetrating injuries were still a significant problem, accounting for $24 \%$ of cases which required admission. Other types of injury were rare, with very few intraocular foreign bodies (IOFBs) or chemical burns. Injuries caused by IOFBs usually produce significant intraocular damage and have a dismal prognosis. Chemical injuries are commonly bilateral and consume resources owing to initial intensive treatment and the need for prolonged topical therapy. The outlook for serious chemical burns is also poor.

OUTCOME

Two children $(2 \%)$ in this series suffered from a serious loss of vision in one eye but no eye required to be enucleated. This is a better outcome for children's injuries than previously reported, where the outcome of paediatric ocular trauma has been noted to be particularly severe. ${ }^{9} 1012131522$ This may reflect changing mechanisms of injury, with more blunt trauma and fewer penetrating injuries and intraocular foreign bodies than seen previously. However, on closer inspection the visual outcome is better than that found in studies which had similar patterns of injury. ${ }^{12} 131524$ An alternative explanation for this improved prognosis may be better trauma management in the form of surgical techniques and medical treatments. Better management may be a factor, especially compared with studies carried out many years ago, but this is only part of the answer as this paediatric subgroup had a better outcome than that of the entire population which was studied. ${ }^{2}{ }^{3}$ Thirteen per cent of the entire population had a poor visual outcome $(2.5 \%$ with final acuities of $6 / 18-6 / 60$ and $10.7 \%$ with acuities of $<6 / 60)^{2}$ compared with only $2 \%$ of the children. The paediatric population would be offered similar management options as the rest of the population, and therefore modern treatment cannot be entirely responsible for the improved outcomes.

Previous studies identified that most ocular injuries in children take place in outdoor locations, ${ }^{81421}$ whereas in this study the home, followed by school, is the most common location for a paediatric ocular injury to take place. These areas tend to have an adult presence with some degree of control and the improved prognosis for this age group may simply reflect the current increased awareness of child safety which has resulted in more supervision.

METHODS OF PREVENTION

Prevention of injury depends, firstly, on identifying the cause and, secondly, targeting this by education and legislation. Some causes of ocular trauma are particularly conspicuous by their absence in this series, indicating that preventative strategies have been effective in certain areas. There were no injuries due to road traffic accidents and these seem to have been effectively eliminated as a cause of eye injury in the young (and in adults) owing to successful implementation of legislation regarding the use of seat belts in the front and back seats of cars. ${ }^{16-18}$ Fireworks, similarly, caused no injuries and this is probably the result of a combination of legislation regarding the sale of fireworks to those younger than 14 years of age and education, which has increased the number of organised displays.

Airgun injuries have a poor prognosis owing to the extensive damage caused by the high velocity pellets and often result in loss of vision or even enucleation. ${ }^{30}$ Legislation alone is not always successful, in that it is illegal for those under 17 years of age to handle firearms unsupervised by an adult, and airguns were responsible for $3 \%$ of injuries in this series. Until recently this has been a very low profile area, although the new firearms legislation in the light of the Dunblane tragedy may now completely eliminate these injuries. In contrast, there is no legislation regarding the safe keeping of domestic chemicals. However, they have been identified as dangerous, mainly because they are sometimes accidentally ingested, and parents are aware that they must be stored safely away from children; this is reflected in the small number of chemical burns found in this study. 
Sports have frequently been reported as a source of major ocular trauma in all age groups, but especially the young. ${ }^{21}{ }^{26}$ Clear cut methods of prevention have been identified in the form of eye protection where indicated (racket sports, hockey) and promoting safe play. The recent introduction of a British standard for eye protection in squash may help to reduce this source of injury as it will be aimed at those starting out in the sport, although many injuries occur because of the haphazard nature of the games which take place on an unsupervised basis.

The dangers of day to day household items are often not evident until it is too late, and such injuries may prove very difficult to prevent. Raising awareness of the dangers in the domestic situation by promoting avoidance and safer practices is the only method available and, although all injuries are, in theory, preventible this may not be easy in the preschool age group in the home. Perhaps factors such as immature motor skills, carelessness, and uncontrolled emotions which are inherent in young children may be more important in causing injury than most preventable causes.

\section{SUMMARY}

This study has identified that serious eye injuries requiring hospital admission in children remain a problem. However, only a small proportion $(2 \%)$ of all children admitted with an eye injury were visually impaired in the affected eye as a result of the injury and none was bilaterally affected. This is a considerable improvement on previous studies and must be viewed as progress, especially as this study has shown that the incidence of ocular trauma in children has reduced and the outcome for this paediatric population is significantly better than in previous studies. Prevention, as the optimum management of trauma, must however remain a priority in order to reduce existing morbidity and costs.

This study has shown that the most common place for a paediatric eye injury to occur is the home, and it may be more difficult to influence the occurrence of domestic trauma, although by continuing to increase parental awareness, supervision may improve and exposure of young children to potentially dangerous objects and situations will be reduced.

We would like to thank all the ophthalmologists in Scotland and their clerical staff, without whose support and assistance this study could not have been conducted; Miss Kate Bullock and Miss Marisa Tomlinson at the Royal College of Ophthalmologists; and Mrs Lynda Rose at Ninewells Hospital Ophthalmology Department.

This study was supported by a grant from the Scottish Home and Health Office, Clinical Resources and Audit Group, grant no CA $91 / 9$.

Parul Desai was supported by core audit funding from the Department of Health for the Royal College of Ophthalmologists, London, to conduct this study.

1 National Society for the Prevention of Blindness. Fact Sheet. Vision problems in the US. New York: National Society for the Prevention of Blindness, 1980.

2 Desai P, MacEwen CJ, Baines P, et al. Incidence of cases of ocular trauma admitted to hospital and incidence of blinding outcome. Br F Ophthalmol 1996;80:592-6.

3 Desai P, MacEwen CJ, Baines P, et al. Epidemiology and implications of ocular trauma admitted to hospital in Scotland. $\mathcal{F}$ Epidemiol Community Health 1996;50:436-41.

4 Agapitos PJ, Noel LP, Clarke WN. Traumatic hyphaema in children. Ophthalmology 1987;94:1238-41.

5 Cole MD, Smerdon D. Perforating injuries caused by darts. Br f Ophthalmol 1988;72:511-4.

6 Luff AJ, Hodgkins PR, Baxter RJ, et al. Aetiology of perforating eye injury. Arch Dis Child 1993;83:682-3.

7 Dhir SP, Shishko MN, Krewi A, et al. Ocular fireworks injuries in children. $\mathcal{f}$ Pediatr Ophthalmol Strabismus 1991;28: ries in $354-5$.

8 Strahlman E, Elman M, Daub E, et al. Causes of paediatric eye injuries. A population based study. Arch Ophthalmol 1990;108:603-6.

9 Niiranen M, Raivio I. Eye injuries in children. Br f Ophthalmol 1981;65:436-8.

10 Rapaport I, Romem M, Kinek M, et al. Eye injuries in children in Israel; a nationwide collaborative study. Arch Ophthalmol 1990;108:376-9.

11 Nelson L, Wilson T, Jeffers JB. Eye injuries in childhood: demography, etiology and prevention. Pediatrics 1989;84: 438-41.

12 Umeh RE, Umeh OC. Causes and visual outcome of childhood eye injuries in Nigeria. Eye 1997;11:489-95.

13 Elder MJ. Penetrating eye injuries in children of the West Bank and Gaza strip. Eye 1993;7:429-32.

14 Grin TR, Nelson LB, Jeffers JB. Eye injuries in childhood. Pediatrics 1987;80:13-7.

15 Garrow A. A statistical enquiry into 1000 cases of eye injuries. Br F Ophthalmol 1923;7:65-80

6 Mackay GN. Incidence of trauma to the eyes of car occupants. Trans Ophthalmol Soc UK 1975;95:311-4.

17 Vernon SA, Yorston DB. Incidence of ocular injuries from road traffic accidents after introduction of seat belt legislation. F Soc Med 1984;77:198-200.

18 Hall NF, Denning AN, Elkington AR, et al. The eye and the seat belt in Wessex. Br f Ophthalmol 1985;69:317-9.

19 Maltzmann BA, Pruzon H, Mund ML. A survey of ocular trauma. Surv Ophthalmol 1976;21:285-90.

20 Schein OD, Hibberd PL, Shingleton BJ, et al. The spectrum and burden of ocular injury. Ophthalmology 1998;95:300-5.

21 Canavan YM, O'Flaherty MJ, Archer DB, et al. A ten year survey of eye injuries in Northern Ireland 1967-76. Br f Ophthalmol 1980;64:618-25.

22 Takvam JA, Midelfart A. Survey of eye injuries in Norwegian children. Acta Ophthalmol 1993;72:500-5.

23 Ilsar M, Chirambo M, Belkin M. Ocular injuries in Malawi. Br F Ophthalmol 1988;95:300-5.

24 The Directorate of Information Services, Information and Statistics Division, National Health Service in Scotland, Management Executive, Edinburgh, 1991.

25 KarlsonTA, Klein BEK The incidence of acute hospitaltreated eye injuries. Arch Ophthalmol 1986;104:1473-6.

26 MacEwen CJ. Eye injuries: a prospective survey of 5671 cases. Br f Ophthalmol 1989; 73:888-94.

27 MacEwen CJ. Sport associated eye injury; a casualty department survey. Br f Ophthalmol 1987;71:701-5.

28 Lambah P. Some common causes of eye injury in the young. Lancet 1962;2:1351-3.

29 Eagling EM. Perforating injuries of the eye. Br F Ophthalmol 1976;60:732-6.

30 Moore AT, McCartney A, Cooling R. Ocular injuries associated with the use of airguns. Eye 1987;1:422-9. 